\title{
An Ethical Puzzle for University Administrators
}

\author{
Craig W. Somerton \\ Michigan State University
}

\begin{abstract}
$\underline{\text { Abstract }}$
It has long been recognized that ethical behavior is an essential element of an engineer. Considerable attention has been given to ethics in engineering education. Some programs include a full course in ethics, while others integrate ethical issues throughout their curriculum; but all programs need to create a culture where ethical behavior is prized and unethical behavior is not accepted. This culture must be grounded in the behavior of the faculty and administrators. With rampant student cheating and plagiarism, the faculty and administration must set the example. This paper considers an ethical dilemma that is quite often encountered by administrators and presents three possible solutions to this puzzle. Each alternative is analyzed in terms of its ethical ramifications. I hope that this paper may elicit some discussions among faculty and administrators and may lead to some contemplation in terms of changing the standard operating practice.
\end{abstract}

\section{The Puzzle}

Here is the puzzle. An engineering administrator has just received a request from a company dealing with one of the undergraduate degree programs in the college and how it is addressing the company's needs for engineering graduates. This company is a major employer of the college's graduates and over the years has provided significant financial contributions to the college. Hence, it is imperative that the administrator respond in a timely and positive fashion to the inquiry. It turns out that the administrator does not have the expertise to respond directly, after all an administrator cannot know everything, and the request is sent down the line, finally arriving on the desk of a faculty member who is very knowledgeable on the subject. A few days later (actually very timely considering that it is summer and this faculty member is not officially on salary), the administrator receives an electronic version of a report (with the faculty member listed as author) written on the topic of inquiry. Though the report is believed to be factual, it is not as positive as the administrator may like. What to do?

\section{$\underline{\text { Three Solutions }}$}

There appears to be three possible approaches to bring this to closure:

1. The administrator writes a cover letter for the report, in which it is given a more positive spin, and sends it and the report off to the company.

2. The administrator schedules an appointment with the faculty member to sit down and revise the report to give it a more positive spin, and then sends the report to the company under both names. 
3. The administrator takes the electronic version of the report, modifies it to give it a more positive spin, and sends it out under only the administrator's name.

Let us now consider the ethical pluses and minuses of each of these approaches.

At a first glance, it might appear that solution \#1 presents no ethical quandaries. Credit is being given to the author of the report, however, by adding a cover letter that somewhat contradicts the report; the administrator has left their faculty member hanging out to dry. With leadership being one of the roles of an administrator, this solution certainly shows poor leadership and even violates the ethics of leadership, which calls for a leader to protect their followers. In terms of an ethical role model for engineering students, this solution would seem to lie somewhere between neutral and poor.

The second solution is certainly the most ethical of the three proposed solutions. It is also the one that will take the most effort by the administrator for its implementation. However, the interaction between the faculty member and the administrator required to revise the report can be very positive for the administrator. It allows that the faculty member should leave the interaction with very positive feelings about the administrator (good for the administrator) and the administrator should leave the interaction with a deeper understanding of a program for which they have responsibility (also good for the administrator). The extra effort will be a value added.

Without a doubt, solution \#3 is highly unethical. In Figure 1 the plagiarism policy for my department is shown. This policy is distributed with the course syllabus on the first day of class for all undergraduate courses offered by the department. It was developed due to continuing problems associated with academic dishonesty, which sometimes emerged due to student ignorance. The administrator who would implement the third solution is clearly violating points A-1 and A-3 below. It is also interesting to note that if the faculty member anticipated a solution \#3 then, according to this policy, the faculty member is also guilty of committing plagiarism through points B-1 and B-2 in the policy. Another aspect is the issue of intellectual property that is significantly emphasized in academia. It is common practice in industry to have underlings write memos or reports for upper management that are then forwarded to the customer or board of directors as coming solely from the management. The argument is made that the underlings work for management and, therefore, their work is management's work. Certainly academia does not work in this fashion. The vast majority of faculty would say that they do not work for the administrators. Nearly all universities have safeguards in place with respect to the intellectual property rights of faculty members and, even though, the normal focus is research, there is no reason that it should not also include intellectual property generated through service activities. So it would seem that the administrator who chooses solution \#3 would be committing plagiarism and violating the faculty member's intellectual property rights.

\section{Final Remarks}

Of the three solution alternatives that have been proposed for the ethical puzzle, only the second solution appears to be completely ethical. The other solutions either violate the ethics of leadership, intellectual property rights, or are outright plagiarism. In either case, the other solutions provide a very poor ethical role model for engineering students. If we hope to instill 
strong ethics in our students, crucial to the engineering profession, engineering educators must lead by example in all of their professional endeavors, including administration.

\section{CRAIG W. SOMERTON}

Craig W. Somerton is an Associate Professor and Associate Department Chair of Mechanical Engineering at Michigan State University. He teaches in the area of thermal engineering including thermodynamics, heat transfer, and thermal design. Dr. Somerton has research interests in computer design of thermal systems, transport phenomena in porous media, and application of continuous quality improvement principles to engineering education. He received his B.S. in 1976, his M.S. in 1979, and his Ph.D. in 1982, all in engineering from UCLA. 


\section{Figure 1 Department Plagiarism Policy}

\section{Plagiarism Policy \\ Department of Mechanical Engineering}

Plagiarism is not tolerated in the Department of Mechanical Engineering. It shall be punished according to the student conduct code of the University. Integrity and honesty are essential to maintain society's trust in the engineering profession. This policy is intended to reinforce these values.

For the purpose of this policy, plagiarism means presenting, as one's own, without proper citation, the words, work or opinions of someone else.

A. You commit plagiarism if you submit as your own work:

1. Part or all of an assignment copied from another person's assignment, including reports, drawings, web sites, computer files, or hardware.

2. Part or all of an assignment copied or paraphrased from a source, such as a book, magazine, pamphlet, web site, or web posting, without proper citation

3. The sequence of ideas, arrangement of material, pattern or thought of someone else, even though you express them in your own words. Plagiarism occurs when such a sequence of ideas is transferred from a source to a paper without the process of digestion, integration and reorganization in the writer's mind, and without acknowledgement in the paper.

B. You are an accomplice in plagiarism and equally guilty if you:

1. Knowingly allow your work, in preliminary or finished form, to be copied and submitted as the work of another.

2. Prepare an assignment for another student, and allow it to be submitted as his or her own work.

3. Keep or contribute to a file of assignments with the clear intent that these assignments will be copied and submitted as the work of anyone other than the originator of the assignment. (The student who knows that his or her work is being copied is presumed to consent to its being copied.)

(based upon the MSU English Department's policy on plagiarism at: http://www.msu.edu/unit/engdept/undergrad/plagiarism.html) 